\title{
PENERAPAN TEOREMA BRUNER PADA PEMBELAJARAN TRIGONOMETRI
}

\author{
Nyamik Rahayu Sesanti \\ Dosen Pendidikan Matematika Universitas Kanjuruhan Malang \\ Email: nyamik.malang@gmail.com
}

\begin{abstract}
Abstrak
Trigonometri merupakan materi pendukung untuk mata kuliah lainnya, seperti kalkulus 2, kalkulus peubah banyak, kalkulus lanjut, struktur aljabar 1 dan persamaan diferensial. Oleh sebab itu, mahasiswa harus dapat menguasai konsep trigonometri secara matang agar bisa memahami mata kuliah tersebut . Selain itu materi trigonometri diberikan kepada siswa SMA di kelas X, XI, dan XII, sehingga mahasiswa sebagai calon guru harus sudah menguasainya sebagai bekal yang dapat dimanfaatkan pada saat PPL di SMA untuk semua kelas dan pada saat menjadi guru SMA. Tujuan yang akan dicapai dalam penelitian ini adalah mendeskripsikan penerapan pembelajaran Teorema Bruner pada trigonometri dan mengetahui hasil belajar mahasiswa setelah penerapan Teorema Bruner dalam pembelajaran trigonometri. Jenis penelitiannya adalah Penelitian Tindakan Kelas. Subyek penelitian terdiri 36 mahasiswa yang memiliki kemampuan heterogen. Data yang dikumpulkan kemudian dianalisis secara kuntitatif dan kualitatif. Pembelajaran yang dilaksanakan pada penelitian ini berdasarkan Teorema Bruner yaitu teorema kontruksi,teorema contras dan variasi, dan teorema koneksi. Hasil penelitian menunjukkan mahasiswa mampu untuk mengkonstruksi konsep dasar trigonometri dan memberikan contoh yang bervariasi dan kontras. Mahasiswa juga mampu menjelaskan kembali konsep dasar trigonometri kepada temannya. Proses koneksitas mahasiswa juga semakin meningkat dengan adanya pengajuan pertanyaan-pertanyaan yang berkaitan dengan konsep dasar trigonometri. Dengan demikian hasil belajar mahasiswa juga meningkat.
\end{abstract}

\section{Kata kunci: Trigonometri, Teorema Bruner, Hasil belajar}

\begin{abstract}
Trigonometry is a supporting material for other courses, such as calculus 2, algebra 1 and the structure of differential equations. Therefore, students should be able to master the concepts of trigonometry carefully in order to understand the course. In addition trigonometry material given to high school students in the class X, XI, and XII, so that students as prospective teacher must have mastered it as a provision that can be utilized at the time of PPL in high school for all classes and at the time of becoming a high school teacher. The objectives to be achieved in this research is to describe the application of learning Bruner theorem in trigonometry and know the learning outcomes of students after the application of Theorem Bruner in learning trigonometry. Type of research is classroom action research. The subjects were 36 students who have heterogeneous capabilities. Data collected and analyzed by quantitative and qualitative. Learning undertaken in this study is based on a theorem Bruner namely construction theorems, contras and variations theorems, and connections theorems. The results show the student is able to construct the basic concepts of trigonometry and provide examples of varied and contrasting. Students are also able to explain the basic concepts of trigonometry back to his friend. Connectivity process students are also increasing with the submission of questions relating to the basic concepts of trigonometry. Thus the learning outcomes of students also increased.
\end{abstract}

Keywords: Trigonometri, Teorema Bruner, learning outcomes

Trigonometri adalah materi yang penting bagi mahasiswa karena materi trigonometri merupakan pendukung mata kuliah yang lain. Matakuliah kalkulus 2, terdapat materi integral trigonometri dan substitusi trigonometri. Matakuliah

kalkulus lanjut, terdapat materi
menghitung integral rangkap ganda dengan
menggunakan koordinat kubub, koordinat
bola, dan koordinat tabung. Untuk dapat
menyelesaikan permasalahan integral
tersebut maka mahasiswa seharusnya


sudah menguasai materi trigonometri. Mata kuliah persamaan differensial, terdapat materi menurunkan fungsi trigonometri dan menyelesaikan selesaian umum dari persamaan differensial baik yang temasuk persamaan differensial linear dan homogen. Untuk dapat menyelesaikan permasalahan tersebut, tentunya materi trigonometri sudah dikuasai dengan baik. Pada stuktur aljabar 1, terdapat operasi fungsi dengan kriteria fungsi yang digunakan adalah fungsi aljabar dan trigonometri untuk menunjukkan grup atau bukan. Sehingga pengetahuan tentang trigonometri seharusnya sudah tertanam dengan baik.

Materi trigonometri juga diberikan kepada siswa SMA di kelas X, XI, dan XII, sehingga mahasiswa sebagai calon guru harus sudah menguasai sebagai bekal yang dapat dimanfaatkan pada saat PPL di SMA untuk semua kelas dan pada saat menjadi guru SMA.

Materi trigonometri yang begitu populer diberikan dan dipelajari serta banyak berhubungan dengan materi lainnya maka mahasiswa harus dapat menguuasai dengan baik. Atas dasar tersebut, modal dasar yang dibutuhkan mahasiswa dalam mempelajari dan melaksanakan pembelajaran di kelas sudah dimilikinya. Sebagai implikasinya, mahasiswa tidak perlu lagi merasa waswas pada saat melaksanakan pembelajaran dan menyelesaikan permasalahan yang berkaitan dengan trigonometri. Walaupun demikian, fakta yang ada menunjukkan kondisi yang berbanding terbalik. Seharusnya mahasiswa yang berasal dari inputan SMA sudah dapat menguasai materi trigonometri dengan baik sehingga dapat menyelesaikan setiap persoalan yang berkaitan dengan materi tersebut.

Hanya saja, kondisi pemahaman mahasiswa Universitas Kanjuruhan Malang pada materi trigonometri masih perlu ditingkatkan. Mahasiswa hanya bisa menyebutkan bentuk final dari rumus bentuk jumlah dua sudut pada trigonometri, rumus bentuk selisih dua sudut pada trigonometri, rumus sudut rangkap pada trigonometri. Mereka belum bisa mengkonstruksi dan menemukan sendiri rumus-rumus tersebut dan bagaimana proses perolehan rumus tersebut belum dapat menjelaskan. Mahasiswa juga tidak mengikuti prosedur dalam mengerjakan soal trigonometri, sehingga menyebabkan kesalahan secara keseluruhan.

Komponen materi yang diujikan dibedakan pada 3 kategori yaitu (1) materi untuk mengetahui sejauh manakah mahasiswa dapat mengingat rumus, (2) materi tentang deskripsi perolehan rumus, dan (3) materi tentang penerapan dari rumus itu dalam kehidupan sehari-hari. Ketiga kategori tersebut selaras terhadap matematika yang memiliki keterkaitan dengan kehidupan sehari-hari. Permasalahan yang dihadapi oleh mahasiswa dalam kehidupannya memerlukan pengetahuan dan stragei pemecahannya, dimana kedua hal tersebut dapat diperoleh dalam belajar matematika. Hal ini sesuai dengan tujuan matematika itu diajarkan di sekolah yaitu (1) melatih cara berpikir dan bernalar dalam menarik kesimpulan, (2) mengembangkan aktivitas kreatif yang melibatkan imajinasi, intuisi, dan penemuan dengan mengembangkan pola pemikiran, (3) mengembangkan kemampuan mengembangkan masalah, dan (4) mengembangkan kemampuan menyampaikan informasi atau mengkomunikasikan (Setyono, Zaini, 2010:1).

Upaya yang dapat dilakukan untuk meminimalisir kendala yang dihadapi oleh mahasiswa, peneliti menawarkan beberapa tahapan dalam kegiatan pembelajaran dengan pendekatan teorema Bruner. Bruner mengusung beberapa teorema yang dapat dipakai yaitu teorema kontruksi, teorema notasi, teorema contras dan variasi, dan teorema koneksi. Teorema 
kontruksi, cara terbaik belajar matematika dilakukan dengan mengkontruksi baik dilakukan secara mandiri maupun kelompok. Proses kontruksi dapat terjadi dengan mudah dan mungkin dapat mengalami kesulitan. Untuk meminimalisir kesulitan yang dihadapi, Hudojo (1988) menyarankan untuk dilakukan dengan memberikan bimbingan. Hal tersebut perlu dilakukan karena siswa memungkin perlu pengetahuan dasar.

Apabila mahasiswa sudah dapat mengkontruksi pengetahuan dengan bantuan penjelasan dosen yang sederhana maka selanjutnya masuk pada teorema kontras dan variasi. Pada teorema kontras dan variasi, untuk mendukung aktivitas pada tahap ini perlu diberikan berbagai macam contoh sehingga pemahaman mahasiswa semakin komplit. Sedangkan untuk teorema koneksi, memfokuskan pada keterkaitan antara materi yang satu dengan materi lainnya dan bahkan penerapan materi terhadap permasalahan sehari-hari.

Gagne (Karso, 2014: 1.29) menyebutkan bahwa dalam belajar matematika ada dua obyek, yaitu obyek langsung belajar matematika dan obyek tidak langsung belajar matematika. Obyek langsung meliputi fakta, operasi, konsep, dan prinsip. Sedangkan obyek tidak langsung mencakup kemampuan menyelidiki, memecahkan masalah, disiplin diri, bersikap positif, dan tahu bagaimana semestinya belajar. Hudoyo (2005:135) menegaskan bahwa agar proses belajar matematika terjadi, bahasan matematika seyogyanya tidak disajikan dalam bentuk yang sudah tersusun secara final, melainkan siswa dapat terlibat secara aktif dalam menemukan konsep-konsep, struktur-struktur sampai kepada teorema atau rumus-rumus.

Teorema Bruner terdiri dari (1) teorema kontruksi, (2) teorema notasi, (3) teorema kontras dan variasi, (4) teorema koneksi. Pada penelitian ini, teorema notasi tidak digunakan karena teorema ini cenderung menggunakan notasi-notasi terhadap suatu obyek konkret menjadi obyek semi abstrak (gambar) dan simbol. Teorema Bruner merupakan pengembangan terhadap teori Piaget yang mengelompokkan tingkatan perkembangan berfikir individu berdasarkan tingkat usianya. Lebih lanjut, Piaget mendeskripsikan bahwa usia $0-2$ tahun, tingkat berfikir anak berada pada tahap sensori-motor, $2-7$ tahuan, tingkat berfikir anak berada pada tahap preoperasional, 7 - 11 tahuan, tingkat berfikir anak berada pada tahap operasional konkrit, dan usia diatas 11 tahun, tingkat berfikir anak berada pada tahap operasional formal.

Cara belajar anak menurut tingkatan usia memiliki perbedaan. Misalnya pada usia 7 - 11 tahun, usia ini anak sudah berada di tingkat sekolah dasar. Untuk melatih anak berfikir matematika perlu melibatkan benda-benda konkrit untuk membantunya. Hal ini karena anak belum bisa menjelaskan mengapa $(-1) \times(-1)=1$ dan $(-1) \times 1=-1$ dan proses pembuktian secara deduktif belum dapat dilakukan. Berbeda dengan usia di atas 11 tahun, individu pada usia ini sudah dapat membuktikan mengapa jika a, b anggota bilangan riil maka $\mathrm{a}=0$ atau $\mathrm{b}=0$, mengapa jumlah sudut dalam segitiga adalah $180^{\circ}$ dan lainnya.

Individu pada usia di atas usia 11 tahun sudah memiliki keanekaragaman pengetahuan dalam fikirannya, sehingga kegiatan konstruksi dapat dengan mudah terjadi. Untuk mendukung kegiatan tersebut, tidak menutup kemungkinan masih memerlukan bimbingan untuk mengarahkan kepada alur berfikir yang benar. Apabila tidak diberikan bimbingan, maka pengetahuan itu murni hasil pengembangan dalam fikirannya.

Penerapan Teorema Bruner pada pembelajaran matematika bisa diterapakan pada individu usia di atas usia 11 tahun. 
Materi matematika disajikan dengan melibatkan siswa secara aktif dalam menemukan konsep-konsep, strukturstruktur sampai kepada teorema atau rumus-rumus. Siswa juga bisa menyajikan konsep-konsep secara bervariasi dan mengkaitkan dengan kehidupan seharihari.

Trigonometri merupakan satu sajian materi pada mata kuliah Matematika Dasar 3. Ruang lingkup materi trigonometri yang diberikan kepada mahasiswa yang menempuh mata kuliah tersebut yaitu (1) perbandingan, (2) jumlah dan selisih sudut, (3) Fungsi Trigonometri, (4) Grafik fungsi trigonometri, (5) Persamaan trigonometri, dan (6) Pertidaksamaan trigonometri. Kompetensi yang harus dicapai oleh mahasiswa yaitu menguasai dan terampil mengaplikasikan konsep dalam memecahakan permasalahan kehidupan sehari-hari. Materi dasar trigonometri ini bisa disajikan pada pembelajaran dengan menerapkan Teorema Bruner.

Tujuan dari penelitian ini adalah mendeskripsikan pembelajaran trigonometri dengan menerapkan teorema Burner, respon mahasiswa terhadap penerapan teorema Bruner dalam pembelajaran trigonometri, hasil belajar mahasiswa setelah diterapkannya teorema Bruner dalam pembelajaran trigonometri.

\section{Metode Penelitian}

Pendekatan penelitian menggunakan kualitatif karena memiliki kesamaan karakteristik dengan pendapat Moleong (2006:8-13). Data yang diperlukan meliputi hasil validasi instrumen, hasil pekerjaan mahasiswa dalam mengkonstruksi konsep dasar trigonometri, hasil pekerjaaan mahasiswa pada soal-soal variasi, hasil penjelasan mahasiswa terhadap konsep tersebut dan hasil belajar mahasiswa. Keseluruhan data diambil dari subyek penelitian sebanyak 36 mahasiswa yang memiliki kemampuan heterogen. Sesuai dengan jenis penelitian yang digunakan, maka analisis terhadap data yang diperlukan merujuk pada pendapat Miles dan Huberman (1992:18) yang meliputi: (1) reduksi data, (2) penyajian data, dan (3) kesimpulan. Selanjutnya dianalisis dengan menggunakan analisis kuantitatif untuk data validasi dengan menggunakan rumus persentase nilai ratarata $(\mathrm{NR})=\frac{\sum \text { Skor Perolehan }}{\sum \text { Maksimal }} x 100 \%$ dengan kriteria (1) valid tanpa revisi $75 \% \leq \mathrm{NR}$ $\leq 100 \%$, (2) belum valid dengan sedikit revisi $(50 \% \leq \mathrm{NR}<75 \%$ ), (3) belum valid dengan banyak revisi $(25 \% \leq \mathrm{NR}<50 \%)$, (4) tidak valid.

Untuk mengumpulkan data yang diperlukan dalam penelitian ini, maka intrumen yang digunakan meliputi rencana Perkuliahan materi trigonometri sebanyak 8 kali pertemuan, lembar observasi perkuliahan, angket respon mahasiswa, dan tes uraian.

\section{Hasil dan Pembahasan}

Penerapan teorema konstruksi yang dilaksanakan pada pembelajaran adalah mengkontruksi konsep dasar trigonometri yang tertuang pada Lembar Kerja Mahasiswa. Konsep yang dikontruksi adalah perbandingan trigonometri $\sin \alpha^{\circ}$, $\cos \alpha^{\circ}$ dan $\tan \alpha^{\circ}$ dan perbandingan kebalikan dari cosecant, secan dan cotangent. Proses pengkonstruksian kosep dasar trigonometri ini, diawali dengan pembuktian dua segitiga yang kongruen. Kemudian mahasiswa membuktikan dari dua segitiga yang kongruen tersebut, maka perbandingan sisi-sisi yang bersesuaian selalu tetap. Pada kegiatan ini semua kelompok bisa membuktikan dan menemukan konsep dasar trigonometri. Salah satu contoh pekerjaan kelompok adalah: 


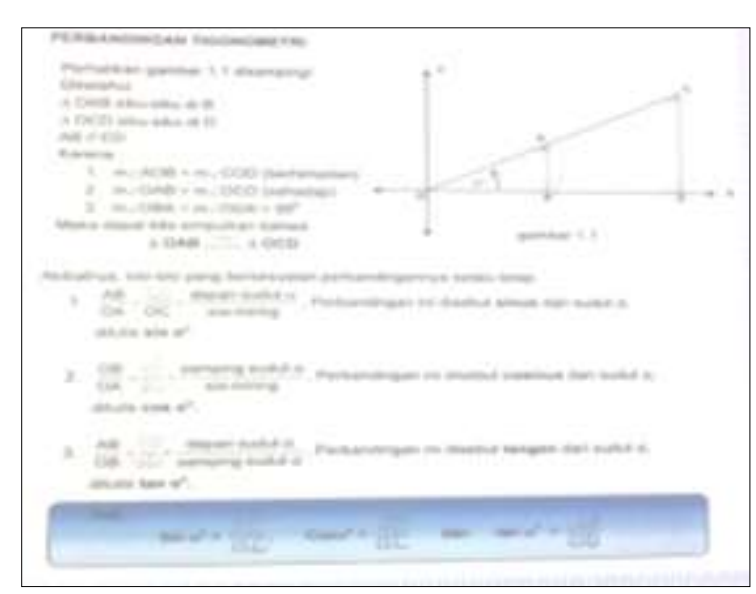

Gambar 1 Penemuan konsep

Konstruksi penentuan nilai sinus, cosinus dan tangen pada sudut $30^{\circ}$ melalui segitiga sama sisi dengan panjang sisi 2 $\mathrm{cm}$. Untuk penentuan nilai sinus, cosinus dan tangen pada sudut $45^{\circ}$ melalui segitiga siku-siku sama kaki. Hamper semua kelompok membutuhkan bimbingan ketika menentuka nilai sinus, cosinus dan tangen pada sudut $0^{\circ}$ dan sudut $90^{\circ}$.

Konsep yang akan dikonstruksi pada konsep aturan-aturan identitas trigonometri dan rumus perbandingan trigonometri melalui langkah-langkah penemuan aturanaturan identitas trigonometri dan rumus perbandingan trigonometri. Semua kelompok berhasil menemukan aturanaturan identitas trigonometri. Salah satu contoh jawaban kelompok adalah

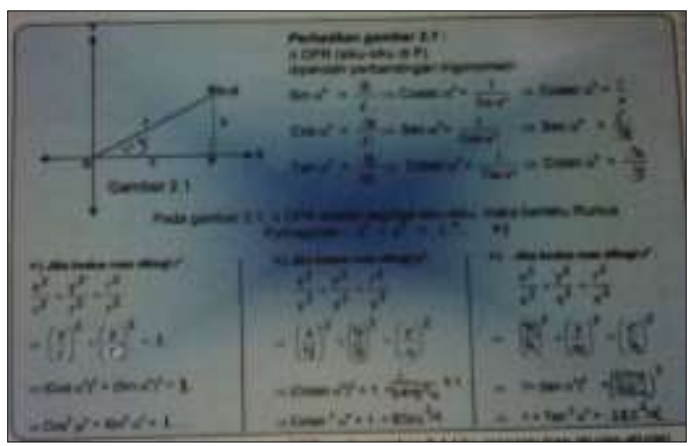

Gambar 2 Penemuan Identitas Trigonometri
Pada proses pengkonstruksian aturan-aturan identitas trigonometri, dengan memperhatikan segitiga OPR, mahasiswa memperoleh aturan perbandingan trigonometri dari sinus, cosec, cosinus, seccan, tangen dan cotangent. Segitiga OPR adalah segitiga siku-siku, sehingga berlaku teorema phytagoras.

Penerapan teorema kontras dengan memberikan soal yang kontras atau berbeda dengan konsep dasar trigonometri. Contoh soalnya adalah

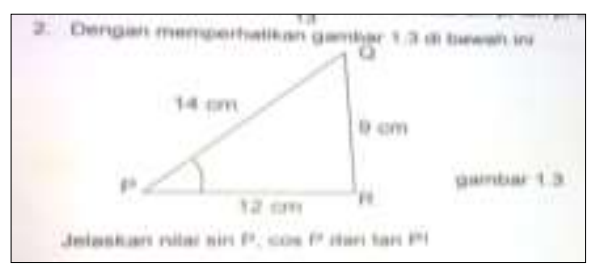

\section{Gambar 3 Contoh soal}

Soal ini tidak memenuhi segitiga siku-siku, sehingga tidak berlaku konsep dasar trigonometri. Pada tahap ini ada tujuh kelompok dari sembilan kelompok yang menjawab tidak benar. Mereka kurang teliti dalam melihat konsep dasar trigonometri yang telah dipelajari. Mereka tidak membuktikan segitiga PQR bukan segitiga siku-siku, tetapi langsung menentukan nilai sin $\mathrm{P}, \cos \mathrm{P}$ dan $\tan \mathrm{P}$. Salah satu contoh pekerjaan kelompok yang tidak benar adalah

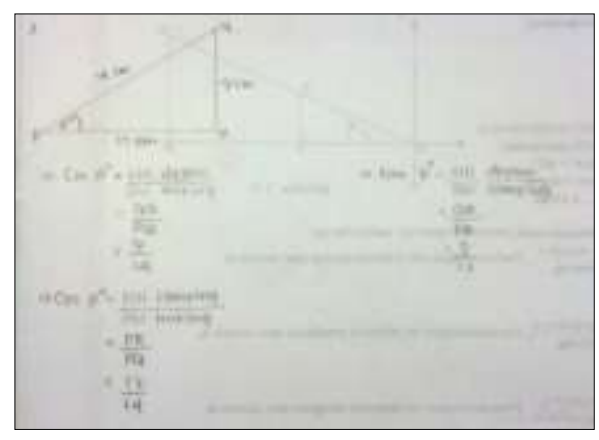

Gambar 4 Pekerjaan soal yang salah

Penerapan teorema kontras selanjutnya dengan memberikan soal yang jawabannya bisa dengan dua variasi cara. 
Jawaban soal tersebut diperoleh dengan cara penerapan teorema phytagoras dan konsep dasar trigonometri. Adapun contoh soalnya adalah sebagai berikut:

Diketahui segitiga siku-siku.

Panjang sisi miringnya adalah $3 \sqrt{2}$ cm. Jika besar salah satu sudutnya adalah $45^{\circ}$, berapakah panjang sisi-sisi yang lain?.

Ada dua kelompok mahasiswa yang menjawab dengan menggunakan teorema phytagoras dan lainnya menggunakan konsep dasar trigonometri. Kelompok yang menjawab dengan teorema phytagoras memberikan penjelasan bahwa kelompok tersebut memang menjawab seperti itu, belum terfikir untuk menjawab dengan konsep dasar trigonometri. Sedangkan kelompok satunya sengaja menjawab dengan teorema phytagoras memberikan penjelasan, apakah jawabannya sama dengan menggunakan konsep dasar trigonometri. Sembilan kelompok yang menjawab dengan menggunakan konsep dasar trigonometri, menjelaskan bahwa kelompok tersebut memang menjawab seperti itu karena materi yang dibahas adalah trigonometri. Hal ini menunjukkan bahwa mereka belum terbiasa untuk memberikan variasi jawaban pada soalsoal yang diberikan dan baru menyadari bahwa soal tersebut bisa dijawab dengan dua variasi.

Penerapan teorema kontras juga dilakukan mahasiswa dengan menyajikan aturan-aturan identitas trigonometri dalam variasi yang lain. Contoh rumus identitas yang disajikan dalam variasi yang lain adalah

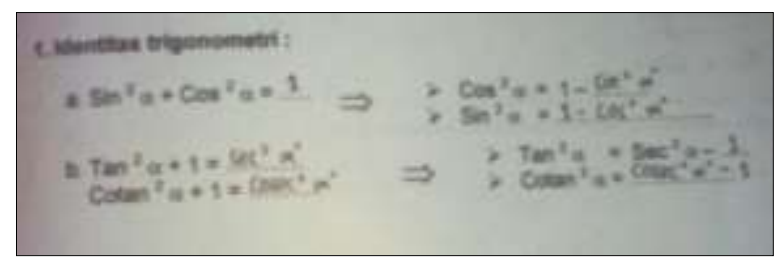

Gambar 6 Bentuk variasi identitas trigonometri
Mahasiswa sudah memahami rumus aturan-aturan identitas trigonometri tersebut. Hanya saja mereka kurang menyadari bahwa aturan-aturan trigonometri tersebut merupakan variasivariasi dari rumus trigonometri. Selama ini mereka hanya menghafalkan rumus-rumus tersebut.

Penerapan teorema koneksi pada pembelajaran ini adalah presentasi hasil pekerjaan kelompok. Pada kegiatan ini, salah satu anggota kelompok wajib menjadi model guru untuk menjelaskan konsep dasar trigonometri di depan kelas. Sedangkan kelompok yang lain memberikan pertanyaan-pertanyaan yang berkaitan dengan konsep tersebut. Pertanyaan yang dismpaikan adalah pertanyaan yang berkaitan dengan konsep teorema phytagoras yang dihubungkan dengan konsep dasar trigonometri. Pada kegiatan ini mahasiswa berdiskusi dan saling bertukar informasi konsep-konsep yang berkaitan dengan trigonometri.

Penerapan teorema koneksi selanjutnya adalah membuktikan identitas trigonometri yang sederhana. Pada kegiatan ini, mahasiswa mengkaitkan antara aturan-aturan identitas trigonometri untuk membuktikan kebenaran dari soal yang diberikan.

Penerapan teorema koneksi juga pada penyelesaian soa-soal yang berkaitan dalam kehidupan sehari-hari. Soal yang pertama adalah soal open ended yang berkaitan dengan pembangunan atap rumah. Soal yang kedua adalah soal yang berkaitan dengan penentuan jarak. Jawaban dari kelompok mahasiswa berbeda-beda. Selanjutnya jawaban tersebut dipresentasikan ke kelompok yang lain sebagai informasi yang berbeda dari kelompok yang lainnya.

Penerapan teorema konstruksi merupakan langkah-langkah untuk menemukan konsep-konsep dalam matematika dengan melibatkan mahasiswa 
sehingga bermakna. Konsep yang diperoleh bukan hanya hafalan sehingga mudah dilupakan. Adanya kegiatan pengkontrusian pengetahuan yang dilakukan oleh siswa dan tugas guru memfasilitasi mahasiswa agar terjadi proses belajar (Zaini\&Mufida, 2013). Jika dalam pembelajaran matematika dilakukan dengan kegiatan transfer maka hal tersebut bertentangan Marpaung (2006) menyatakan bahwa pembelajaran matematika merupakan usaha membantu siswa mengkonstruksi pengetahuan melalui proses.

Penerapan teorema koneksi dengan menjedikan salah satu mahasiswa menjadi model merupakan rangsangan untuk meningkatkan perkembangan intelektual dan ketrampilan dalam menyampaikan konsep trigonometri. Bruner menyatakan bahwa perkembangan intelektual meliputi perkembangan kemampuan berbicara pada diri sendiri atau pada orang lain melalui kata-kata atau lambang tentang apa yang telah dilakukan dan apa yang akan dilakukan (Budiningsih, 40: 2012). Perkembangan kognitif juga ditandai dengan kemampuan mengemukakan kembali pemahamannya dengan alternatif bahasa yang digunakan.

Perkembangan intelektual tersebut sesuai dengan tujuan matematika yang diajarkan di sekolah yaitu (1) melatih cara berpikir dan bernalar dalam menarik kesimpulan, (2) mengembangkan aktivitas kreatif yang melibatkan imajinasi, intuisi, dan penemuan dengan mengembangkan pola pemikiran, (3) mengembangkan kemampuan mengembangkan masalah, dan (4) mengembangkan kemampuan menyampaikan informasi atau mengkomunikasikan (Setyono, Zaini, 2010:1).

\section{Simpulan}

Penerapan teorema Bruner pada pembelajaran trigonometri adalah

a. Teorema konstruksi
Mahasiswa mengkontruksi dan menemukan konsep trigonometri melalui lembar kerja mahasiswa yang diberikan.

b. Teorema perbedaan dan variasi Mahasiswa mengerjakan tugas yang berbeda dan bervaiasi pada trigonometri.

c. Teorema konektivitas

Mahasiswa menjadi model guru untuk menjelaskan konsep yang ditemukannya dan menanggapi pertanyaan-pertanyaan yang muncul dari temannya.

Mahasiswa berperan aktif pada saat pembelajaran, terutama pada penerapan teorema konektivitas yang memberi kesempatan pada mereka untuk menerangkan konsep dan membuat pertanyaan.

\section{Pustaka Rujukan}

Budiningsih, Asri: 2012, Belajar dan Pembelajaran, Jakarta: Rineka Cipta.

Bruner, Jerome: 1977, The Process of Education, London: Harvard University Press.

Hodoyo, H. 2005. Kapita Selekta Pembelajaran Matematika. Malang: PPS UM.

Hudojo, H. 1988. Mengajar Belajar Matematika. Jakarta: Depdikbud.

Karso,dkk. 2014. Pendidikan Matematika 1. Modul Universitas Terbuka tidak diperjual belikan: Jakarta.

Marpaung, Y. 2006. Pembelajaran dengan model PMRI, Makalah Seminar dan Lokakarya, Yogyakarta, PPPG Matematika.

Miles, M. B. dan Huberman, A. M. 1992. Analisis Data Kualitatif. Jakarta: UI-Press.

Moleong L.J. 2006. Metode Penelitian Kualitatif. Bandung : Remaja Rosda.

Zaini\&Mufida. 2013. Kontruksi Pembuktian Teorema Pada 
Matakuliah Geometri Euclid Melalui Aktivitas Think Pair Share. Penelitian dosen pemula. LPPM Universitas Kanjuruhan Malang.

Zaini. 2010. Pembelajaran Melalui Penemuan Terbimbing Untuk Membangun Pemahaman Konsep Irisan Bangun Ruang Siswa SMA N I Paiton. Tesis tidak diterbitkan: Universitas Negeri Malang. 